\title{
Ciencia moderna, planeta torturado Una reflexión crítica sobre el modo eurocéntrico de conocer la naturaleza e intervenir en el medio ambiente
}

\section{Modern science, tortured planet. A critical reflection on the Eurocentric way of to know nature and to intervene in the environment}

\author{
Jorge Polo Blanco* - Eleder Piñeiro Aguiar*
}

\begin{abstract}
Resumen: En este texto teórico-reflexivo indagaremos de forma crítica algunos de los componentes que configuraron el paradigma epistémico de la modernidad europea, considerando que la cuantificación, la matematización y la objetividad mensurable no fueron solamente principios teóricos fundantes de la ciencia moderna, pues constituyeron algo más: fueron los elementos a través de los cuales se levantó una nueva cosmovisión. Con ello, se instauró una nueva manera de comprender e imaginar la naturaleza; y también un nuevo modo de intervenirla y violentarla. Se expondrán algunas teorías críticas, como son el perspectivismo amerindio y la decolonialidad, que han respondido a dicha visión pretendidamente universal y homogénea, concluyendo que pese a la existencia de patrones mundiales de poder y conocimiento, las alternativas para el saber y el actuar sobre el ambiente pasan por decolonizar el método de extracción de recursos; para lo cual no sólo deben revertirse ciertas prácticas económicas y ciertos modelos de acumulación, sino que a su vez debe neutralizarse la violencia epistémica que justifica y ampara dichas prácticas y dichos modelos.
\end{abstract}

Palabras clave: ciencia moderna; modernidad europea; naturaleza; extractivismo; interculturalidad.

\begin{abstract}
In this theoric-reflexiv text, we will investigate critically some of the components that shaped the epistemic paradigm of European modernity, considering that quantification, mathematization and measurable objectivity are not only theoretical principles found in modern science, since they constituted something more: They were the elements through which a new worldview arose. With this, a new way of understanding and imagining nature was established; and also a new way of intervening and violating it.
\end{abstract}

\footnotetext{
* Español. Autor principal. Dr. en Filosofía. Escuela Superior Politécnica del Litoral, Ecuador. Investigador y docente en la Escuela de Diseño y Comunicación Visual (EDCOM), perteneciente a la Escuela Superior Politécnica del Litoral (ESPOL), Guayaquil, Ecuador, hiperbolik1983@hotmail.com

** Español. Autor secundario. Dr. en Antropología, Universidad Adolfo Ibáñez, Chile, elederpa1983@gmail.com
} 
Some critical theories will be exposed, like the Amerindian perspectivism and the decoloniality, that have responded to this supposedly universal and homogeneous vision, concluding that despite the existence of world patterns of power and knowledge, alternatives for the wise and acting on the environment pass through decolonizing the Method of extracting resources; for which not only certain economic practices and some models of accumulation must be reversed, but in turn must neutralize the epistemic violence that justifies and protects such practices and models.

Keywords: Modern science; European modernity; Nature; Extractivism; Interculturality.

Recibido: 8 mayo 2018 Aceptado: 13 junio 2018

\section{Una genealogía de la objetivación moderna y europea de la naturaleza}

En un momento preciso de la historia europea el matematicismo se erigió en uno de los pilares básicos a través de los cuales se construyó el canon del pensamiento científico. La matriz matemática perfilaba los contornos inexorables de todo aquello que podía aspirar a ser definido y conocido de manera rigurosa, y los estándares metodológicos que otorgaban el estatuto de cientificidad a una rama o campo del saber eran, de igual modo, los estándares formales de lo cuantitativo-mensurable. Aquello que no encajara en una matriz matemática, ni siquiera podía llegar a ser catalogado como "real". Ernst Cassirer mostró cómo ese particular modo de conocer se consolidó y fortificó, alcanzando su punto más álgido en el sistema de Newton, a través de un cierto sometimiento formal del mundo. Esa "filosofía de la naturaleza", que así se denominaba en el siglo XVIII, dejó bien asentado que no había nada verdaderamente objetivo sino después de que el material empírico sufriese un particular sometimiento epistémico a manos de las matemáticas. Pero el nuevo paradigma así instaurado no entendía que las matemáticas fuesen únicamente una suerte de instrumental teórico, esto es, un método de cálculo útil para predecir fenómenos naturales; lo matemático era mucho más que eso, puesto que era la propia estructura objetiva del cosmos la que estaba trazada de forma matemática ${ }^{1}$. Es en esta modernidad europea, por lo tanto, cuando cristaliza una nueva mirada sobre la naturaleza; a través de ella, la imagen del universo quedó radicalmente transformada. La forma última de la razón humana, pensada como instancia universal, se adecuaba a la estructura del cosmos porque ambas realidades -razón humana y cosmos- estaban constituidas de forma matemática.

E. A. Burtt señalaba que cuando Aristóteles penetró y permeó el pensamiento medieval en el siglo XIII (convirtiéndose en la filosofía dominante del orbe cristiano), el

1Ernst Cassirer, Filosofía de la Ilustración, México, Fondo de Cultura Económica, 1975, p. 26. 
platonismo nunca quedó enteramente aniquilado, sino que permaneció como corriente subterránea, latente e implícita que acabaría brotando en pensadores como Roger Bacon, Nicolás de Cusa, Giovanni Pico della Mirandola o Giordano Bruno². Es así que, en los primeros albores de la era moderna, en los siglos XV y XVI, se produce un poderoso renacimiento del platonismo y del pitagorismo, aspecto que tuvo notabilísima influencia en esa interpretación plenamente matemática del mundo, que pronto se tornaría hegemónica. Esta corriente platónico-pitagórica, determinante en el albor renacentista y en los inicios mismos de la era moderna, tuvo que derrotar al aristotelismo, toda vez que para éste la naturaleza era tan fundamentalmente cualitativa como cuantitativa. La tendencia triunfante, finalmente, fue aquélla que "consideraba legítima una matemática universal de la naturaleza" y presuponía "que el universo es fundamentalmente geométrico" 3 . Los aristotélicos, que otorgaban a las matemáticas un lugar subordinado, tenían que considerar ridícula toda pretensión de reducir la estructura intrincadamente cualitativa y teleológica de la physis a una homogénea e isotrópica estructura matemática. Pero precisamente eso es lo que empezó a dejar de ser ridículo, extravagante y heterodoxo; el aristotelismo fue derrotado. A partir de entonces, todo aquello que fuese matemáticamente in-objetivable carecía de entidad real; éste sería el único criterio de demarcación a la hora de distinguir un conocimiento verdadero de otro que no era tal.

Las archiconocidas palabras de Galileo, aparecidas en 1623 en Il Saggiatore, constituyen el frontispicio de la nueva cosmovisión europea: la naturaleza es un gran libro escrito en caracteres matemáticos, aseveraba el italiano, y nosotros sólo debemos aprender ese idioma para desvelar todos los secretos del cosmos 4 . He ahí el verdadero significado, la motivación última que fundamenta todo el edificio de la llamada revolución científica moderna. Rechazar la teoría física aristotélica (hasta ese momento indiscutible) suponía oponerse a una física del "sentido común" fundada en la experiencia sensorial: se podría decir, empleando jerga platónica, que la episteme venció definitivamente a lo que en realidad no era sino mera doxa; porque ahora, de lo que se trataba, era de interrogar a la experiencia con presupuestos y conceptos "irreales" (irreales sólo para la percepción sensorial, pero perfectamente reales para la "intuición matemática"), tales como podrían ser un plano absolutamente (esto es, idealmente) liso o una esfera absolutamente (esto es, idealmente) esférica. Al respecto, Alexandre Koyré explicaba lo siguiente: "Galileo, de entrada y conscientemente, se sitúa fuera de la realidad" 5 . Pero situarse fuera de la realidad quiere decir, en este nuevo paradigma, acceder a su estructura matemática subyacente; he ahí la revolución moderna en la comprensión de la naturaleza, aupada sobre ese matematismo platónico-arquimediano. Había emergido una nueva manera de aprehender el mundo, esto es, de construirlo y objetivarlo; pero también la disponibilidad plena de actuar sobre él: clasificándolo, midiéndolo, cuantificándolo, jerarquizándolo, sometiéndolo.

2Edwin Arthur Burtt, Los fundamentos metafísicos de la ciencia moderna, Buenos Aires, Editorial Sudamericana, 1960.

${ }^{3}$ Burtt, op. cit., p. 56.

4Galileo, Antología, Barcelona, Península, 1991, p. 87.

${ }^{5}$ Alexandre Koyré, Estudios galileanos, Madrid, Siglo Veintiuno, 1980, p. 70. 
El tiempo que emerge en el interior de esta matriz epistémica es el tiempo matemáticamente mensurable; el tiempo de la ciencia moderna (temporalidad culturalmente hegemónica en Europa, a partir de entonces) no es más que movimiento en el espacio, esto es, tiempo geométrico. Porque el tiempo de la física así concebida no es el tiempo subjetivo, no es el tiempo vivido, la "duración" de Henri Bergson6. Es, por el contrario, un tiempo mecánico, matemático, cuantitativo, mensurable, abstracto, reversible y espacial; esto es, un tiempo ajeno al tiempo que se percibe en la interioridad de una conciencia humana situada, por añadidura, en un contexto cultural específico. Con Galileo el mundo físico empieza a concebirse como una máquina perfecta cuyos acontecimientos futuros podrían ser absolutamente predichos por quien tuviera pleno conocimiento de todos los movimientos presentes; la necesidad mecánica imperaría sin excepción7. Y la comprensión del mundo así forjada se expresó metafóricamente con una imagen poderosísima: el universo era un enorme reloj, y funcionaba como tal; un mecanismo gigantesco regido por una legalidad mecánica ineluctable ${ }^{8}$. El paroxismo de semejante paradigma se alcanzaría con las tesis deterministas del físico francés Pierre-Simon Laplace, que concebía un espacio-tiempo absolutamente encuadrado, hasta el último de sus átomos, en una causalidad mecánica inquebrantable9.

Y para comprender más cabalmente el desarrollo de esa objetivación moderna y europea de la naturaleza, debemos entender cómo la subjetividad misma quedó forjada con nuevos parámetros: la matematización del mundo alcanzó (penetró) lo más íntimo de la conciencia. Circunstancia que, por cierto, potenció eso que algunos autores han denominado -como veremos después- "colonialidad del saber", principalmente cuando dicho "canon cartesiano" fue sistemáticamente empleado para deslegitimar, denigrar y subalternizar otros saberes producidos por pueblos no-europeos ${ }^{10}$. Pero semejante corolario, que no fue otro que el cartesianismo, cristalizó también en un estándar ideal (unívoco) de validez racional. Porque lo matemático, fuente de toda verdad autoevidente, no depende de ninguna exterioridad: se halla anclado en la razón misma11. La geometría y la aritmética son las ciencias que mejor se acomodan a la contextura íntima y esencial del espíritu humano, pues en ellas se manifiesta de forma ejemplar el funcionamiento analítico que subyace en la médula más constitutiva de nuestra razón, como lo cuenta el propio Descartes en su Discurso del método ${ }^{12}$. Pero esa exigencia general de orden analítico ha de extenderse a todo el conjunto de las disciplinas; ése es el nuevo mandato epistémico. La mirada científica europea se ensambla así en una nueva unidad (o unificación) de la razón, pues ésta es capaz de aplicar una misma matriz a todos sus objetos. Este nuevo paradigma quedaba bien sintetizado en las Reglas de Descartes, cuando sentenciaba que "aquéllos que

\footnotetext{
${ }^{6}$ Henri Bergson, Ensayo sobre los datos inmediatos de la conciencia, Salamanca, Sígueme, 2006.

7Burtt, op. cit., p. 103.

8Peter Galison, Relojes de Einstein y mapas de Poincaré. Los imperios del tiempo, Barcelona, Crítica, 2005.

9P. S. Laplace, Exposición del sistema del mundo, Barcelona, Crítica, 2006, p. 36.

10Walter Mignolo, Historias locales/diseños globales. Colonialidad, conocimientos subalternos y pensamiento fronterizo, Madrid, Ediciones Akal, 2003; Catherine Walsh, "Interculturalidad, conocimientos y decolonialidad", Signo y Pensamiento, Volumen XXIV, No 46, enero-junio, 39-50, 2005.

11Luis Arenas, Identidad y subjetividad. Materiales para una historia de la filosofía moderna, Madrid, Biblioteca Nueva, 2002, pp. 31-32.

12René Descartes, Discurso del método y Meditaciones metafísicas, Madrid, Tecnos, 2002, p. 83.
} 
buscan el recto camino de la verdad no deben ocuparse de ningún objeto del que no puedan tener una certeza igual a la de las demostraciones aritméticas y geométricas ${ }^{13}$. La "buena dirección del espíritu", por emplear una expresión cartesiana, es la que viene determinada por un determinado proceder cuya mejor cristalización ha de verse reflejada en el orden de las ciencias matemáticas. Las máximas de la razón se cumplen y refrendan, de manera ejemplar y arquetípica, en dichas ciencias; y de ahí procede la legitimidad (y el prestigio) de la matemática como ciencia preeminente, convirtiéndose en la que más derecho detenta a la hora de exportar su propio orden interno a todas las demás disciplinas; la que mejor sirve, en último término, para comprender, analizar, imaginar e interpretar la naturaleza.

Para Descartes las matemáticas son el canon de la razón misma; pero lo decisivo es que ese rigor (esa fuente privilegiada y exclusiva de la verdad) procede de la propia interioridad de nuestra conciencia, que se identifica ella misma con un proceder puramente matemático. Descartes lleva el matematicismo a su hipérbole última, porque el matemático es el mejor de los lenguajes para expresar la estructura última del espíritu humano. "La razón humana es ahora coextensiva con su proceder matemático" 14 . Ésa fue la trascendental mutación cartesiana, una verdadera apoteosis de la mathesis universalis, que revolucionó la concepción de la naturaleza, del hombre y de la racionalidad. La certeza de la matemática será transferida a la configuración interna de nuestra subjetividad para, desde ahí, extenderse a todo lo que puede ser conocido. La calculabilidad tiende a permear, de manera creciente, todos los ámbitos de la subjetividad y todas las dimensiones del orden social. Cuerpo-máquina y mente-calculadora son los ejes a través de los cuales se articula la antropología cartesiana, tan influyente en el devenir intelectual y cultural de la Europa moderna. El hombre no es más que una máquina bien organizada; y el pensamiento, en esta nueva concepción, aparece en todo caso como el resorte que rige la maquinaria, la pieza principal que guía el funcionamiento normal de la máquina15. Una tesis que alcanzaría su punto álgido a mediados del siglo XVIII, en la obra de La Mettrie ${ }^{16}$.

El "método científico" así consolidado configuró una visión del mundo muy específica, como bien observó Herbert Marcuse. "La abstracción científica de lo concreto, la cuantificación de las cualidades, que da exactitud tanto como validez universal, envuelven una experiencia concreta específica de la Lebenswelt: un modo específico de «ver» el mundo"17. Pero esa concreta forma de ver, a través de la idealidad absoluta de lo matemático, conlleva una cierta manera de estar instalado en la realidad, un determinado modo de incidir y operar en ella; esa forma de ver el mundo (de objetivarlo) es también -y principalmente- una forma de actuar en él, de transformarlo y violentarlo. "En este proyecto, la cuantificación universal es un prerrequisito para la dominación de la naturaleza"18. Ése es el programa científico-natural de la moderna Europa, el cual a su vez

13René Descartes, Reglas para la dirección del espíritu, Madrid, Alianza, 2003, p. 75.

14Luis Arenas, "De lo uno a lo otro: conocimiento, razón y subjetividad en Descartes", Anales del Seminario de Historia de la Filosofía, No 13, 97-124, 1996, p. 111.

15René Descartes, El tratado del hombre, Madrid, Alianza, 1990, p. 109.

16. O. La Mettrie, El hombre máquina, Madrid, Alhambra, 1987.

17Herbert Marcuse, El hombre unidimensional, Barcelona, Ariel, 1987, p. 191.

18Marcuse, op. cit., p. 191. 
produce una determinada forma de vida y una concreta subjetividad histórica, toda vez que "la ciencia, gracias a su propio método y sus conceptos, ha proyectado y promovido un universo en el que la dominación de la naturaleza ha permanecido ligada a la dominación del hombre: un lazo que tiende a ser fatal para el universo como totalidad"19. Todo artefacto tecnológico es un artefacto político, sigue sosteniendo Marcuse ${ }^{20}$. Y la construcción científico-técnica de lo natural (en base a la nueva y moderna episteme) también fue construyendo lo político-social; ambas dimensiones se hallan profunda y dialécticamente imbricadas ${ }^{21}$.

No debe olvidarse que el dominio técnico de la naturaleza siempre estuvo vinculado a la sobreexplotación de millones de seres humanos, en Europa y fuera de ella. Devastación ambiental y devastación cultural siempre fueron procesos simultáneos, como veremos más adelante. También Horkheimer señaló que el logocentrismo europeo, decantado en ese concepto de razón esencialmente cuantificadora, y cuya máxima expresión teórica fue alcanzada con la filosofía cartesiana, terminó por ser enteramente cómplice de los procesos más alienadores de las sociedades industriales. "Es como si el pensamiento mismo se hubiese quedado reducido al nivel de los procesos industriales, sometido a un plan exacto y convertido, en una palabra, en un elemento fijo de la producción ${ }^{22}$. Esa razón mutilada, reducida a una de sus funciones más nítidamente instrumentales, quedó convertida en mero procedimiento técnico únicamente apto para ejecutar conceptualizaciones y operaciones cuantitativas; se trataba de una racionalidad, y es éste el núcleo del asunto, enteramente reconciliada con los procesos cosificadores y alienantes de la sociedad industrial pues, como señalaron Adorno y Horkheimer, "la razón misma se ha convertido en simple medio auxiliar del aparato económico omnicomprensivo"23. Este ominoso destino de la racionalidad moderna fue propiciado, evidentemente, por la expansión casi irrestricta del modo de producción capitalista. Esa "filosofía cartesiana", caracterizada por una matematización exhaustiva de la conciencia y de la naturaleza, no podía quedar enteramente desvinculada del desarrollo histórico de la empresa capitalista moderna, toda vez que ésta llevaba dentro de sí una mentalidad crecientemente calculadora y contable, tal y como lo tematizara Max Weber ${ }^{24}$.

Los dualismos establecidos por Descartes (sujeto-objeto; mente-cuerpo; objetividad-subjetividad) privilegiaron lo "cultural" (y posteriormente lo civilizado/ilustrado) sobre lo natural, todo lo cual se halla estrechamente ligado a la lógica imperial y eurocéntrica de las naciones industriales capitalistas. “La razón cartesiana se enajena y se exterioriza en el cuerpo-objeto, estableciendo una jerarquía entre la posición de quien indaga -«Europa», la «razón» desincorporada- y quien es objeto «natural», cuerpo «objetivizado» de esa indagación" 25. Y andando el tiempo comprobaríamos cómo todas las reflexiones que, ya en el siglo $X X$, se tejieron en torno a eso que dio en llamarse

19Marcuse, op. cit., p. 193.

${ }^{20}$ Marcuse, op. cit., p. 195.

${ }^{21}$ Marcuse, op. cit., p. 196.

22Max Horkheimer, Crítica de la razón instrumental, Madrid, Trotta, 2002, p. 58.

23Theodor Adorno y Max Horkheimer, Dialéctica de la Ilustración, Madrid, Trotta, 2004, p. 83.

${ }^{24}$ Max Weber, Historia económica general, México, Fondo de Cultura Económica, 1983.

${ }^{25}$ Rita Laura Segato, "Ejes argumentales de las perspectivas de la colonialidad del poder", Revista Casa de las América, N²72, julio-septiembre, 17-39, 2013, p. 28. 
"teorías de la acción racional", concebían una razón humana plenamente identificada con el cálculo (muy cartesianamente) y, en última instancia, la entendían como un dispositivo puramente optimizador ${ }^{26}$. Las relaciones con el mundo natural, en un contexto semejante, solamente podían darse de una cierta manera, como veremos a continuación.

\section{Primero, matematizarla; después, exprimirla, someterla y torturarla}

Martin Heidegger27, comentando una frase del físico y matemático Max Planck, en la que éste aseveraba que "sólo es real lo que se deja medir", señalaba que pertenece a la esencia de la ciencia moderna ese modo de objetivar lo real. La naturaleza sólo aparece para la ciencia en una muy determinada objetivación, a saber, la que viene predeterminada y prefigurada por el puro cálculo de fuerzas, anticipando así su explotación puramente técnica ${ }^{28}$. La racionalidad occidental, y es éste un aspecto crucial, siempre vivió instalada en una radical escisión hombre-naturaleza, por medio de la cual esta última se presentaba siempre como un objeto externo al que dominar y explotar. Tal concepción quedó bien asentada en la filosofía de Francis Bacon, también en el siglo XVII. De una naturaleza así entendida (objetivada) había de extraerse el máximo rendimiento posible, sometiéndola tecnológicamente y exprimiendo hasta su última gota de energía. Una de sus obras fundamentales fue Instauratio Magna (La Gran Restauración), publicada en 1620; en ella encontramos el famoso Novum Organum, donde Bacon se opone frontalmente a la sofistería aristotélica y a la verborragia escolástica; porque el saber no debe ser mera discusión, sino fáctica intervención. El conocimiento de las leyes que gobiernan la naturaleza permite a los seres humanos un control y dominio absolutos sobre ella. Bajo tal perspectiva, la naturaleza debía ser "acosada", "esclavizada" y "torturada hasta arrancarle sus secretos" 29 .

Fruto de esa esclavización que instrumentaliza-cosifica a la naturaleza, para arrancarle de forma ilimitada sus riquezas, surge la honda preocupación por comprender el fenómeno del extractivismo, definido por Eduardo Gudynas de la siguiente manera: "tipo de extracción de recursos naturales, en gran volumen o alta intensidad, y que están orientados esencialmente a ser exportados como materias primas sin procesar, o con un procesamiento mínimo" 30 . No es algo, nuevo como hemos visto. Desde la formación del sistema-mundo moderno, y en concreto en el periodo que va de 1492 al 1700, se conformó no solo un patrón mundial de poder sino toda una forma de entender el mundo bajo cuyo prisma los recursos de la tierra (en su totalidad) estarían subsumidos en la dinámica interna del capital. La naturaleza, así proyectada y cosificada, se refería a esa dimensión externa e inerte que el hombre podía (es más, debía) apropiarse; "naturaleza" concebida como mero material "pasivo y explotable". Una imagen de lo natural que, por lo demás, quedó

\footnotetext{
26Nicholas Rescher, La racionalidad, Madrid, Tecnos, 1993, p. 15.

27Martin Heidegger, Filosofía, ciencia y técnica, Santiago de Chile, Editorial Universitaria, 2003, p. 165.

${ }^{28}$ Heidegger, op. cit., pp. 131-132.

${ }^{29}$ Francis Bacon, La gran restauración (Novum Organum), Madrid, Tecnos, 2011.

${ }^{30}$ Eduardo Gudynas, "Extracciones, extractivismos y extrahecciones: un marco conceptual sobre la apropiación de los recursos naturales", Observatorio del Desarrollo, 18, 1-18, 2013, p. 4.
} 
entrelazada con otras ideas-fuerza de la modernidad europea, señaladas por Aníbal Quijano:

Durante el siglo XVIII, ese nuevo dualismo radical fue amalgamado con las ideas mitificadas de "progreso" y de un estado de naturaleza en la trayectoria humana, los mitos fundacionales de la versión eurocentrista de la modernidad. Esto dio pie a la peculiar perspectiva histórica dualista/evolucionista. Así todos los no-europeos pudieron ser considerados, de un lado, como pre-europeos y al mismo tiempo dispuestos en cierta cadena histórica y continúa desde lo primitivo a lo civilizado, de lo irracional a lo racional, de lo tradicional a lo moderno, de lo mágico-mítico a lo científico. En otras palabras, desde lo no-europeo/pre-europeo a algo que en el tiempo se europeizará o "modernizará" 31.

Desde la antropología marxista Eric Wolf32 concibió la existencia de "pueblos sin historia" y, en ese mismo sentido, abundó el diagnóstico más esclarecedor de Lyotard33, que explicó cómo Occidente generó "grandes relatos", siendo uno de ellos -y quizás el más importante- el mito de una "historicidad evolutiva" desplegada a través de un vector progresista y cuya punta de lanza o vanguardia siempre era Europa, que aparecía así como el verdadero sujeto de la Historia Universal, Hegel dixit. El diagnóstico de una crisis civilizatoria, vinculada a la quiebra de ese mito del "progreso", aparece tematizado con mucha penetración en la obra del economista y ambientalista mexicano Enrique Leff:

La problemática ambiental emerge como una crisis de civilización: de la cultura occidental; de la racionalidad de la modernidad; de la economía del mundo globalizado. No es una catástrofe ecológica ni un simple desequilibrio de la economía. Es el desquiciamiento del mundo al que conduce la cosificación del ser y la sobreexplotación de la naturaleza; es la pérdida del sentido de la existencia que genera el pensamiento racional en su negación de la otredad ${ }^{34}$.

El "problema medioambiental", que deviene ya crisis civilizatoria, hunde sus raíces en el tipo de racionalidad que pone en juego la cultura occidental. La "muerte entrópica del planeta" es el resultado de un determinado modo de ser y de estar en el mundo que, a la postre, ha resultado ser suicida y ecologicida. Concluía Leff que "el conocimiento se ha vuelto contra el mundo, lo ha intervenido y dislocado" 35 . Y, en la estela de la Escuela de Frankfurt, comprende que el problema hunde sus raíces en la profunda cosificación del mundo y de la naturaleza ejercida por esa racionalidad avasalladora:

La crisis ambiental irrumpe en el momento en el que la racionalidad de la modernidad se traduce en una razón anti-natura. No es una crisis funcional u operativa de la

\footnotetext{
${ }^{31}$ Aníbal Quijano, “Colonialidad del Poder, Eurocentrismo y América Latina”, en Lander, Edgardo (Comp.), Colonialidad del Saber, Eurocentrismo y Ciencias Sociales. Perspectivas latinoamericanas, Buenos Aires, CLACSO, 2000, p. 225.

32Eric R. Wolf, Europa y los pueblos sin historia, México, Fondo de Cultura Económica, 1987.

33J. F. Lyotard, La condición posmoderna. Informe sobre el saber, México, Ediciones Rei, 1990.

${ }^{34}$ Enrique Leff, Racionalidad ambiental. La reapropiación social de la naturaleza, México, Siglo Veintiuno, 2004, p. IX.

${ }^{35}$ Leff, op. cit., p. IX.
} 
racionalidad económica imperante, sino de sus fundamentos y de las formas de conocimiento del mundo. La racionalidad ambiental emerge así del cuestionamiento de la sobreeconomización del mundo, del desbordamiento de la racionalidad cosificadora de la modernidad, de los excesos del pensamiento objetivo y utilitarista ${ }^{36}$.

Desde el pensamiento crítico latinoamericano se han considerado algunas de estas propuestas en clave marxista, pero siendo al mismo tiempo críticas con un pretendido dogmatismo canónico; y, por otra parte, sirviéndose de ciertas teorías y conceptos para contextualizarlos en las problemáticas autóctonas de la región. Así, por ejemplo, Bolívar Echeverría expone que el ethos "realista" fue el que prevaleció en la modernidad occidental capitalista, pero simplemente fue uno de los posibles, toda vez que se impuso al ethos barroco, al clásico y al romántico. Esto se debió, principalmente, a que primó el "valor de cambio" sobre el "valor de uso", a la vez que no permitió contradicciones al interior de una ética-ascética del trabajo proveniente de una moral protestante, individualista y competitiva $^{37}$. Y la prevalencia de semejante ethos tuvo enormes implicaciones para el mundo de lo natural, desde luego. Se impuso una racionalidad económica y tecnocientífica que, a medida que fue expandiendo su potencia, fue "socavando las bases de sustentabilidad de la vida" 38 . He ahí la radicalidad del problema, que en absoluto puede contemplarse como una cuestión meramente coyuntural; muy al contrario, el gravísimo "problema medioambiental" se halla enraizado profundamente en la matriz epistémica (y, por ende, en las lógicas socioeconómicas) de la modernidad europea. En este sentido, podemos observar el análisis realizado a principios del siglo pasado por Mariátegui ${ }^{39}$, para quien las problemáticas campesinas -los derechos sobre la tierra y una repartición equitativa de recursos para los indígenas, entre otros- deberían de ir de la mano de una teoría-praxis definida en clave de lucha de clases. Su conceptualización crítica, por lo tanto, entroncaba el análisis marxista del trabajo y la subsunción del mismo al capital con las problemáticas campesinas y de redistribución de la tierra. Lo económico, lo cultural y lo medioambiental no pueden entenderse como problemáticas ajenas, pues se hallan inextricablemente unidas.

Es cierto, debemos señalar, que buena parte de la tradición marxista europea asumió dogmáticamente una tesis muy controvertida, a saber, que el desarrollo sin límite de las fuerzas productivas habría de conducir necesariamente a un afloramiento (a modo de implosión) de las contradicciones internas del modo de producción capitalista; momento definitivo y crucial en el que, por fin, se abriría la posibilidad de transitar hacia un orden social distinto y mejor. Walter Benjamin advertía que esta concepción era un error terrible sostenido por la nefasta filosofía de la historia de la socialdemocracia, toda vez que la aceleración continua de la historia (esto es, el incremento constante de las fuerzas productivas) sólo podía conducir al desastre, y no a ningún estadio postcapitalista deseable. Benjamin imaginaba, por el contrario, que el socialismo había de ser más bien un

\footnotetext{
${ }^{36}$ Leff, op. cit., p. X.

37Bolívar Echeverría, Modernidad, mestizaje cultural, ethos barroco, México, UNAM, 1994.

${ }^{38}$ Leff, op. cit., p. X.

39José Carlos Mariátegui, Siete ensayos de interpretación de la realidad peruana, Caracas, Ayacucho, 2007.
} 
"freno de emergencia" que detuviera ese proceso histórico descontrolado, y avasallador con la naturaleza ${ }^{40}$.

Karl Polanyi, que fue uno de los críticos más agudos de los dramáticos quebrantos antropológicos derivados de la implantación del capitalismo, señaló también que la "tierra" quedó afectada de forma intensísima por el afianzamiento de un sistema de mercado prácticamente omnímodo y omnipotente; esto es, la "ficción mercantil" hizo su imparable y destructora incursión en la naturaleza misma. Y, en ese sentido, Polanyi anticipa en sus reflexiones algunos elementos decisivos del ulterior pensamiento crítico puesto en juego por la ecología política:

La tierra es parte de la naturaleza y está tan poco pensada para la venta como el hombre. Las ficciones legales y económicas bajo las que la tierra puede ser puesta bajo el control del mercado del suelo son, en general, análogas a las que encontramos en el caso del trabajo. En realidad, la tierra es el hábitat del hombre, el emplazamiento de sus actividades, la fuente de su vida, el lugar de su seguridad, de las estaciones y la tumba. Ni siquiera los suelos pueden soportar el tratamiento comercial. Erosionados, arrasados, pulverizados, todas las regiones corren el riesgo de la regresión al bosque primario, el pantano o el desierto. El derroche de recursos daña nuestro futuro [...] Tan cercana es la vida del hombre a la de la naturaleza, que a menos que el destino económico del producto del suelo sea organizado de manera tal que permita llevar una vida normal a aquellos que trabajan la tierra, la agricultura será destruida ${ }^{41}$.

La calamitosa deshumanización de una agricultura organizada toda ella en base al beneficio capitalista produce, asimismo, un agotamiento excesivo de los recursos; el hábitat natural, mercantilizado y comercializado hasta la raíz, es exprimido hasta la extenuación. Polanyi, por lo tanto, estaba apuntando ya a los nefastos efectos de una mercantilización irrestricta de la tierra y de todos los recursos naturales que de ella proceden; y entendió que, para evitar la devastación mercantil del mundo natural, la organización de dichos recursos habría de fundamentarse en una institucionalidad ajena al sistema de mercado. Esto es, la única ecología política consecuente habría de ser una ecología anticapitalista.

Rosa Luxemburgo observaba en Die Akkumulation der Kapitalen que la procreación natural de la clase obrera no era la única fuente de la que el capital extraería incesante y renovada materia sobre la que fundamentar su reproducción ampliada; la reproducción del capital nunca se limitó (jamás lo haría) a ese plano, toda vez que el proceso de acumulación necesita vitalmente de zonas sociales ( $\mathrm{y}$, por supuesto, naturales) todavía no mercantilizadas y aún no enroladas en el poderoso mecanismo de las modernas relaciones de producción. El capital siempre requirió perentoriamente extenderse hacia esas zonas, subsumirlas; y esa tendencia habrá de perpetuarse (pues es la lógica inmanente del sistema) hasta que dichas zonas, en un futuro, dejen de existir ${ }^{42}$. Porque en el límite, la mecánica acumulativa del capital necesitaría movilizar todas las fuerzas productivas de la

40Walter Benjamin, La dialéctica en suspenso. Fragmentos sobre la historia, Santiago de Chile, LOM, 2009, p. 58.

${ }^{41}$ Karl Polanyi, “El eclipse del pánico y las perspectivas del socialismo”, en César Rendueles (Eds.), Los límites

del mercado. Reflexiones sobre economía, antropología y democracia, Madrid, Capitán Swing, 123-126, 2014, p. 125.

42Rosa Luxemburgo, La acumulación del capital, México, Grijalbo, 1967, p. 278. 
tierra, incluyendo dentro de su esfera fuerzas naturales y energías humanas que no estaban aún dentro de su órbita. Todo lo "precapitalista" (entendiendo por tal, de un modo genérico, cualquier realidad natural o relación humana que implique una exterioridad fáctica y positiva con respecto a la lógica del capital) terminaría por quedar incluido en el vasto circuito planetario de la acumulación capitalista.

Como ha señalado Jason W. Moore, la acumulación de capital se identifica plenamente (consustancialmente) con la apropiación sin límite de la naturaleza global. Pero semejante proceso ha de comprenderse desde "la perspectiva del capitalismo como ecología-mundo: una civilización diferenciada y unificada a través de la cual la acumulación de capital, la producción de la naturaleza, y la búsqueda del poder forman una totalidad histórico-mundial" 43 . El capitalismo es, de forma esencial, una manera muy específica (e insólita) de objetivar (cosificar-cuantificar) la naturaleza. En ese sentido, la explotación del trabajo humano y la apropiación de la naturaleza extra-humana son dos procesos entrelazados en una dinámica sistémica de mercantilización sin fin. "La acumulación interminable de capital y la apropiación interminable de la Tierra forman un proceso histórico-mundial singular ${ }^{4 \prime}$. Las fronteras de la mercantilización se amplían sin cesar, y así ha sido históricamente, en sucesivas olas de acumulación. O, dicho de otra forma, el modo capitalista de acumulación económica requiere inexorablemente (de lo contrario, colapsaría) de una permanente e interminable apropiación de la Tierra.

Un ejemplo muy evidente de todo ello lo encontramos en la reciente fusión de dos compañías trasnacionales, ya de por sí enormes y poderosas. Bayer, en efecto, anunció a mediados de septiembre de 2016 la adquisición de la empresa de biotecnología Monsanto, por unos 66.000 millones de dólares. Se fraguó, mediante esa operación, un monopolio que afecta de forma trágica a grandes zonas del planeta, generando monocultivos intensivos donde antes existían multicultivos y barbechos; prácticas que impiden que se dé un adecuado remplazo de la tierra y que, a su vez, producen dependencia del producto en campesinos e indígenas. Semejantes procedimientos, en el medio y largo plazo, pueden desembocar en la desertificación de grandes extensiones antaño fértiles. Pero la devastación ecológica y la degradación antropológica van de la mano, una vez más, puesto que se genera un proceso de aculturación violenta que altera por igual la vida comunitaria y el equilibrio medioambiental: donde antes existían semillas autóctonas, trabajadas de una forma tradicional, ahora opera un solo modelo comercializado por Monsanto, que a su vez acapara los derechos de propiedad, apropiándose así de todo el proceso productivo. El derecho a la tierra y los modos de vida tradicionales son destruidos, mientras que el hábitat natural es depredado de forma irresponsable y criminal; pero ambos acontecimientos, hacemos énfasis en ello, son fruto de una misma lógica. Tenía toda la razón Rosa Luxemburgo, indudablemente, y lo comprobamos con horror cuando vemos que hasta las semillas (véase el caso de la empresa transnacional Seminis) quedan subsumidas en la lógica acumulativa del capital.

43J. W. Moore, "El auge de la ecología-mundo capitalista. Las fronteras mercantiles en el auge y decadencia de la apropiación máxima", Laberinto, No 38, 2013, 9-26, p. 16

44Moore, op. cit., p. 18. 
Por su parte, Edgardo Lander ${ }^{45}$ llama la atención acerca de cómo se están desarrollando procesos de biopiratería que involucran a Estados, grandes empresas, organismos internacionales, etc., y cuyo fin último es despojar a la naturaleza de todas sus riquezas para beneficios enteramente privados. Es así que cuando Eduardo Galeano ${ }^{46}$ inició Las venas abiertas de América Latina exponiendo que la división internacional del trabajo significó que unos países se especializaron en ganar y otros en perder, se refirió, entre otros aspectos, a cómo los países del Centro (recordemos que Galeano hablaba desde la fecunda óptica de la Teoría de la Dependencia, desarrollada en los años 70 en suelo latinoamericano) extraían materias primas y recursos en/a las zonas de la periferia para ser consumidos por las élites de las potencias coloniales; y gracias a esto, entre otras cosas, se produjo la Revolución Industrial y el desarrollo de la moderna Europa capitalista, "una civilización «ecologicida» al punto que hoy día no sabemos si la especie humana u otras especies sobrevivirán a la civilización occidental" 47 . Una geopolítica, una geoeconomía, una geocultura y, por qué no decirlo así, una geoepistemología que se fueron ensamblado hasta construir un proyecto civilizatorio radicalmente incompatible con la sostenibilidad del hábitat natural mundial.

Alberto Acosta ha denominado a este proceso "saqueo", esto es, un inmenso dispositivo depredador a través del cual no sólo se extraen minerales o petróleo, sino también flora y fauna ${ }^{48}$. El extractivismo "tiene consecuencias que no se remiten solamente a la pauperización económica de los trabajadores mineros, sino también a los procesos destructivos de la vida y la ecología planetarias"49. Pero, además, Gudynas distingue los términos extractivismo y extrahección; esta última se produce cuando aquél, además, conlleva considerables dosis de violencia, atentando contra los derechos de indígenas, campesinos, mujeres, pueblos afrodescendientes, etc. La extrahección, por lo tanto, es un concepto más amplio y complejo, toda vez que a los daños puramente ambientales hay que sumar un plus de violencia política y exterminio cultural. Se trata de una misma maquinaria económica, sostenida por una misma episteme, depredando el hábitat natural y destrozando otros mundos humanos ${ }^{50}$.

En múltiples territorios del planeta a los campesinos/indígenas se les subsume, a la fuerza, en las lógicas del capital transnacional, obligándoles a entrar en dinámicas de mercado neoliberales y exhortándolos, en último término, a convertirse en "emprendedores de sí mismos" 51 . El modus vivendi de estas poblaciones queda mermado y, en ocasiones, destruido: desplazamiento de su territorio ancestral o tradicional,

\footnotetext{
${ }^{45}$ Edgardo Lander, "Ciencias sociales. Saberes coloniales y eurocéntricos", en La colonialidad del saber: eurocentrismo y ciencias sociales. Perspectivas latinoamericanas, Caracas, Faces- UCV / Unesco-Iesalc, 2000.

${ }^{46}$ Eduardo Galeano, Las venas abiertas de América Latina, Madrid, Siglo XXI, 2004.

47Ramón Grosfoguel, “Del «extractivismo económico» al «extractivismo epistémico» y «extractivismo ontológico»: una forma destructiva de conocer, ser y estar en el mundo", Tabula Rasa, 24, 123-143, 2016, p. 130.

${ }^{48}$ Alberto Acosta, "Post-crecimiento y post-extractivismo: dos caras de la misma transformación cultural", en Gustavo Endara (Edit.), Post-crecimiento y Buen Vivir. Propuestas globales para la construcción de sociedades equitativas y sustentables, Quito, FES Ecuador-ILDIS, 93-122, 2014.

${ }^{49}$ Grosfoguel, op. cit., p. 127.

50Gudynas, op. cit.

51Michael Foucault, Nacimiento de la Biopolítica. Curso en el Collège de France (1978-1979), México y Buenos Aires, Fondo de Cultura Económica, 2007.
} 
confiscación de tierras, exclusión $u$ otras formas de violencia física y simbólica. Montenegro-Perini expone cómo la gubernamentalidad foucaultiana ${ }^{52}$ cristaliza, en contextos semejantes, en conceptos como los de eco-gubernamentalidad 53 y medioambientalidad ${ }^{44}$. Se trata, en último término, de formas de "gobernar la naturaleza" completamente afines a las lógicas acumulativas de capital. Para ello, el autor toma como ejemplo el ecoturismo neoliberal, en el Guaviare (Amazonía colombiana), que despoja a los campesinos, no sin conflictos y brutales tensiones, y además culpabilizándolos y acusándolos de querer permanecer en una situación de "atraso" o "no desarrollo" 55.

Otro tanto sucede con las industrias mineras en México, que gastan al año 12.000 millones de litros de agua. Está por ver si la reciente victoria de AMLO revertirá la tendencia de gobiernos anteriores, los cuales dieron múltiples concesiones a estas empresas privadas que practicaron una minería depredadora. Un ejemplo significativo de contaminación fue el perpetrado por el Grupo México, que vertió al río Sonora 40 millones de metros cúbicos con abundantes metales pesados. Si damos el salto al Ecuador, comprobamos cómo este país andino denunció a la multinacional Chevron en un caso muy mediático, encabezado por las protestas indígenas en la zona de Sucumbíos, en la frontera con Colombia. Más de 80.000 toneladas de residuos dañaron el ecosistema de Lago Agrio, a lo largo de 25, años en una zona de medio millón de hectáreas. Protestas indígenas de este tipo parecen un asunto meramente local, pero no lo es. También tenemos un caso en Colombia, donde una empresa carbonífera expulsó a 35 comunidades indígenas y afro asentadas en la zona noreste del país, en la Guajira; poblaciones desplazadas y resistentes al proceso de esclavitud colonial que, tras más de 400 años de luchas, son despojadas por esta industria extractiva. $\mathrm{O}$ el caso de Venezuela, donde aumenta el contrabando, no sólo de bienes primordiales, sino también la extracción ilegal (en zonas fronterizas) de madera, oro, diamantes y coltán. Semejantes prácticas dañan la integridad cultural y económica de los productores locales, y aumenta la violencia en diversas comunidades del país. Los ejemplos podrían multiplicarse ad infinitum. Con el fin de detener estos procesos, en Ecuador se llevó a cabo una interesante propuesta, consistente en "dejar el petróleo bajo tierra". El gobierno de Rafael Correa, con serias preocupaciones ecológicas, se comprometería a no extraer más crudo en la zona del Yasuní-ITT a cambio de que varios países del mundo pagasen una cuota, y así poder preservar una zona megadiversa inserta en el corazón de la Amazonía; intentó, en suma, globalizar un problema sólo aparentemente local. El cálculo era que, frente a los 72.000 millones de dólares que se obtendrían con la extracción, los principales gobiernos del mundo (los que más contaminan, por cierto) ayudarían al desarrollo social del Ecuador pagando una suerte de indemnización por el mencionado importe, con el fin de evitar la extracción contaminante. Pero la propuesta no llegó a buen término (apenas se obtuvo un

\footnotetext{
52Michael Foucault, "La gubernamentalidad”, en M. Foucault, Obras esenciales. Volumen III: Estética, ética y hermenéutica, Barcelona, Paidós, 175-198, 1999.

${ }_{53}$ Astrid Ulloa, The Ecological Native. Indigenous Peoples' Movements and Ecogovernmentality in Colombia, New York, Routledge, 2005.

${ }^{54}$ Arun Agrawal, Environmentality. Technologies of Government and the Making of Subjects, Durham and London, Duke University Press, 2005.

55Iván Montenegro-Perini, "Ecoturismo, gubernamentalidad neoliberal y despojos en la Amazonia colombiana", Universitas Humanística, (84), 2017: 35-73.
} 
3\% de lo solicitado a países como Alemania, Canadá, EE.UU., etc.,), con lo cual el presidente Correa decidió continuar con la extracción, pues no podía renunciar a la obtención de esos insumos con el objetivo de implementar políticas públicas de ayuda a los sectores sociales más pobres y vulnerables, lo cual le acarreó múltiples críticas y nuevas demandas indígenas en la región y en todo el país, con el colectivo "Yasunidos" a la cabeza. A veces, el "biocentrismo radical" y la lucha contra la pobreza son incompatibles, una contradicción irresoluble para los gobiernos progresistas que cuentan con dichos recursos naturales en su territorio ${ }^{56}$.

La precarización de la vida es uno de los atributos definitorios de la contemporaneidad, no sólo en Occidente sino en todo el planeta ${ }^{57}$. Una de las técnicas que se ha venido utilizando para llegar a dicha condición es precisamente la de "expulsar", tal como expone Saskia Sassen en una de sus obras más recientes58; "ser expulsado" configura, en efecto, un patrón recurrente desde los inicios de la modernidad capitalista. Además de visibilizar casos de persecuciones por motivos de religión, exilios de distinta índole, búsquedas de asilo o refugio por parte de migrantes, esta autora analiza cómo varios procesos en todo el mundo están interrelacionados y engarzados por la lógica planetaria del capital, con el fin de generar nuevos espacios para industrializar, implementar monocultivos intensivos, edificar en terrenos donde se debe expulsar previamente a comunidades enteras, etc. $\mathrm{O}$, incluso, se producen expulsiones debido a desertificaciones y/o inundaciones provocadas por la intensificación fabril que devasta el hábitat ecológico. Zygmunt Bauman ${ }^{59}$ es esclarecedor en este sentido, por cuanto muestra que una de las especialidades del capitalismo global es generar parias humanos, desechos, "vidas desperdiciadas", elementos transitorios que pasan por el mercado como mano de obra barata frente a otros que, sencillamente, son desechados en el basurero del progreso.

\section{Apropiación/destrucción capitalista de la naturaleza y crítica epistémico-política desde el Sur}

Debe comprenderse que el sistema-mundo moderno (capitalista, y esencialmente colonial) llevaba aparejado una cierta episteme, como ha sostenido Aníbal Quijano:

Desde el siglo XVII, en los principales centros hegemónicos de ese patrón mundial de poder, en esa centuria no por acaso Holanda (Descartes, Spinoza) e Inglaterra (Locke, Newton), desde ese universo intersubjetivo fue elaborado y formalizado un modo de producir conocimiento que daba cuenta de las necesidades cognitivas del capitalismo: la medición, la cuantificación, la externalización (u objetivación) de lo cognoscible respecto del conocedor, para el control de las relaciones de las gentes con la naturaleza

\footnotetext{
56Jorge Polo Blanco, "Mercantilización de la naturaleza, biocentrismo radical, extractivismo y desarrollo humano. Las inevitables paradojas de una política pública que reconoce derechos intrínsecos a la naturaleza", Revista de Filosofía, Universidad del Zulia, Venezuela, № 87, 2017: 48-70. ISSN:

57Judith Butler, Vida precaria: el poder del duelo y la violencia, Barcelona, Paidós, 2006.

58Saskia Sassen, Expulsiones: brutalidad y complejidad en la economía global, Buenos Aires, Katz, 2015.

59Zygmunt Bauman, Vidas desperdiciadas. La modernidad y sus parias, Buenos Aires, Paidós, 2005.
} 
y entre aquellas respecto de ésta, en especial la propiedad de los recursos de producción ${ }^{60}$.

Y es que, en la conformación histórica del "sistema-mundo moderno/colonial" 61, la violencia ha sido ejercida en un plano físico, pero también en lo simbólico y en lo epistémico, siendo la naturaleza un lugar más de colonialidad. La noción de colonialidad se refiere al hecho primordial e insoslayable de que, a pesar de haber finalizado el colonialismo económico-político clásico (con la independencia formal de las Repúblicas latinoamericanas con respecto a las administraciones españolas, portuguesas, francesas, etc.), siguen existiendo procesos y dispositivos que, como gramáticas culturales perdurables, todavía colonizan mentes, imaginarios, subjetividades, cuerpos, conocimientos, saberes. "El colonialismo no es un periodo histórico superado, un fósil inerme. Es una semilla que aún da sus frutos, reproduciendo una característica administración del pensamiento que sustenta un sistema de extracción de la mayoría de la población del planeta"62. Por supuesto, la naturaleza (esto es, los modos de conocerla y las formas de vivir en ella), no es ajena a esta secular situación de colonialidad.

Esa colonialidad del poder y del saber implica, además, que son unos los que están ejerciendo el dominio geopolítico, geoeconómico y geocultural: explotando, excluyendo, subalternizando e invisibilizando a otros, a saber, los situados en las múltiples periferias del sistema-mundo capitalista. Pero si bien hasta aproximadamente los años sesenta del pasado siglo observábamos que el pretendido universalismo occidental se imponía al Sur desde el Norte, lo cierto es que existen desde hace unos cincuenta años corrientes en sentido inverso (y en sentido Sur-Sur) que revelan una progresiva pérdida de hegemonía por parte de esos "modos de conocer" creados (e impuestos) desde el eurocentrismo secular. El imperialismo cultural europeo, podríamos decir, ha perdido poder e influencia al menos en el plano epistémico; lo "occidentalocéntrico" ha sido cuestionado desde múltiples flancos ${ }^{63}$. Pero esa "rebeldía epistémica" movilizada desde diversos lugares (y América Latina ha jugado en esto un papel primordial) también ha incidido en un plano más explícitamente político, abriendo nuevas posibilidades a la construcción de una crítica más multidimensional del capitalismo. Han surgido en el Sur global, por lo tanto, diversas preocupaciones por pensar "otros mundos posibles", como rezaba la ya mítica consigna del Foro Social Mundial.

Algunas de estas propuestas, si bien no permiten todavía construir una enmienda a la totalidad del sistema capitalista, al menos esbozan una respuesta crítica a la hegemonía neoliberal y a su aparataje de conocimiento. Han emergido nuevas gramáticas de lo político ${ }^{64}$, por cuanto los grandes relatos de la modernidad capitalista han finalizado, al

60Aníbal Quijano, “Colonialidad del poder y clasificación social”. Journal of World-Systems Research, Volume 6, Issue 2, Special Issue Festschrift for Wallerstein, 342-386, 2000, p. 343.

${ }^{61}$ Mignolo, op. cit.

62Liliana Suarez Navas, "Colonialismo, gobernabilidad y feminismos poscoloniales", en Descolonizando el feminismo: teorías y prácticas desde los márgenes, Madrid, Cátedra, 2008, p. 24.

63Ramón Grosfoguel, "Racismo/sexismo epistémico, universidades occidentalizadas y los cuatro genocidios/epistemicidios del largo siglo XVI", Tabula Rasa, 19, 2013: 31-58.

64Paolo Virno, Gramática de la multitud. Para un análisis de las formas de vida contemporánea, Madrid, Traficantes de Sueños, 2003. 
menos en un cierto sentido. Debemos adentrarnos en las diversas formas en las que el Sur se está pensando a sí mismo, lo que a su vez permitirá repensar las lógicas hegemónicas del Norte. Qué propuestas epistémicas han surgido en los últimos años en el Sur global, he ahí un asunto crucial; una cuestión que, en última instancia, también permitirá responder desde el mundo académico al interrogante de cuál habrá de ser el sujeto de una probable revolución en el siglo XXI. ¿Hablaremos, quizás, de revoluciones "sin sujeto", como ha señalado Santiago Castro-Gómez ${ }^{65}$ en la estela de Hardt y Negri66? En cualquier caso, si Marx desechaba (aunque al final de su vida, debemos decirlo, rechazó parcialmente esta tesis) al campesinado como sujeto capaz de llegar a concretarse en "clase para sí", siendo así un colectivo incapaz de poner en juego un proceso revolucionario, las dinámicas de los dos últimos siglos no han confirmado esa hipótesis, sino todo lo contrario, por cuanto diversas reivindicaciones campesinas han servido de cortapisas a las dinámicas predatorias del capital. El descubrimiento de historiadores marxistas, como son los estudios de E.P. Thompson ${ }^{67}$ referentes a las revueltas populares desencadenadas por el incremento del precio del pan en aquella Inglaterra que ya iniciaba su revolución industrial, son un claro ejemplo de cómo los movimientos contestatarios pueden llevarse a cabo por "sujetos sociales" que nada tienen que ver con un proletariado fabril bien organizado en estructuras político-sindicales. En ese sentido, cabe destacar el papel que han jugado categorías como lo "subalterno" y lo "decolonial" en Latinoamérica y en otras regiones del mundo; encontramos, en esos contextos, propuestas medioambientalistas muy radicales (anticapitalistas, incluso) que sin renunciar al marxismo clásico lo engarzan con problemáticas indígenas, feministas y decoloniales.

Por comenzar con el pensamiento decolonial, podemos señalar que Catherine Walsh expone que existe (además de una colonialidad del poder, del ser y del saber) una colonialidad de la naturaleza, por cuanto se ha impuesto "una división que descarta por completo la relación milenaria entre seres, plantas y animales como también entre ellos, los mundos espirituales y los ancestros (como seres también vivos)"68. El pensamiento decolonial es heredero de varias tradiciones que, sin pretender generar un dogma de conocimiento, ponen su atención en una crítica al eurocentrismo. Recoge conceptos y teorías de la subalternidad asiática ${ }^{69}$, del sistema-mundo de Immanuel Wallerstein, de la teología/filosofía de la liberación de Enrique Dussel, de la "pedagogía del oprimido" de Paulo Freire e incluso del posestructuralismo francés, entre otros muchos.

Recordemos que el concepto de Abya-Yala significaría, aproximadamente, "tierra en plena madurez"; por lo tanto, las visiones dualistas occidentales entrarían en conflicto con las concepciones indígenas holísticas, que integran a la naturaleza en un mismo mundo material, espiritual y simbólico. En estas cosmovisiones la naturaleza no aparece como un ente externo, no existe esa escisión o fractura tan propia del universo cultural occidental.

\footnotetext{
65Santiago Castro-Gómez, Revoluciones sin sujeto. Slavoj Žižek y la crítica del historicismo posmoderno, México, Akal, 2015.

66 Michael Hardt y Antonio Negri, Multitud. Guerra y democracia en la era del Imperio, Buenos Aires, Debate, 2004. ${ }^{67 E d w a r d}$. P. Thompson, "La economía moral de la multitud en la Inglaterra del siglo XVIII", Revista de Occidente, $\mathrm{N}^{\mathrm{o}} 133,1974:$ 54-125.

${ }^{68}$ Catherine Walsh, "¿Son posibles unas ciencias sociales/culturales "otras"? Reflexiones en torno a las epistemologías decoloniales", Revista Nómadas, N²6, abril, 2007, 102-112, p. 106.

69Ranajit Guha, Las voces de la historia y otros estudios subalternos, Barcelona, Crítica, 2002.
} 
En la actualidad, una corriente de pensamiento denominada perspectivismo amerindio, encabezada por Viveiros de Castro en Brasil, defiende que no es que existan varias culturas y una única naturaleza, sino todo lo contrario: una única cultura (la especie humana) con particularidades que cristalizan en formas diversas de imaginar y comprender a la naturaleza (y de relacionarse con ella). Si en la cosmología occidental en el principio todo era naturaleza y, sólo al final de un largo proceso, pudo emerger la humanidad, en los mitos amazónicos lo primero fue la humanidad, y sólo posteriormente el mundo pasó de lo humano a lo animal, lo vegetal y lo mineral. Esa inversión cosmogónica tiene, desde luego, efectos prácticos en lo que a la comprensión de la naturaleza se refiere. Y, desde luego, la objetividad científica de la que hablábamos al comienzo de este trabajo ha conllevado múltiples violencias (epistémicas, simbólicas y materiales) e hirientes unilateralidades, siendo la más perjudicial de todas ellas la de tomar a la naturaleza como un mero objeto infinitamente explotable. De lo que se trata, en vistas de lo cual, es de descolonizar el pensamiento para poder comprender que los mitos indígenas son también filosofía en un plano de igualdad con la occidental; porque, además, en esos mitos normalmente despreciados por el saber occidental pueden hallarse otras formas menos agresivas y dañinas de relacionarse con el mundo natural 70 .

Phillip Descola, que realizó varios trabajos de campo en comunidades schuar y achuar de la Amazonía ecuatoriana, se hallaba igualmente situado en la órbita del perspectivismo; aseveraba, con deje provocador, que "la naturaleza no existe". En ese sentido, sostenía que las amenazas medioambientales y ecológicas son consecuencia de una cosmovisión en la cual la naturaleza es un objeto radicalmente escindido, algo que tiene sus seculares o milenarios antecedentes en la filosofía griega, tal y como ya expusimos en la introducción. En Más allá de naturaleza y cultura se postula que el ser humano bien podría relacionarse con la naturaleza de otra manera, no cosificadora y no individualista ${ }^{71}$. El antropólogo francés está convencido de que la división entre naturaleza y cultura, propia de Occidente pero no de otras sociedades, es la causa del calentamiento global y otros acuciantes problemas medioambientales. Existen culturas que manejan otro tipo de representaciones, otras ontologías, en la que no existe nítida distinción entre humanos y no humanos; culturas en las que las relaciones interpersonales incluyen a las plantas, a los animales e incluso a otros elementos de la naturaleza, como las piedras. En esos otros mundos, evidentemente, la naturaleza no vive en trance permanente de ser exprimida y explotada sin límite.

Arif Dirlik ${ }^{72}$, en relación con lo anterior, ha señalado el papel crucial que los indigenismos jugarán en la actualidad mundial, por cuanto las reivindicaciones territoriales y de recursos -luchas locales- conllevarán al mismo tiempo decisivas repercusiones en las formas globales de entender la civilización en su relación (criminal o respetuosa) con la naturaleza. Lo indígena, desde lo local, puede albergar una tremenda potencialidad a la hora de cuestionar modelos de desarrollo destructivos y suicidas;

70Eduardo Viveiros de Castro, Metafísicas caníbales. Líneas de antropología postestructural, Buenos Aires, Madrid, Katz, 2010.

71Philippe Descola, Más allá de naturaleza y cultura, Buenos Aires, Amorrortu, 2012.

${ }^{72}$ Arif Dirlik, The poscolonial aura. Third world criticism in the age of global capitalism, Boulder, Westview Press, 1997. 
modelos socioeconómicos (sustentados en cierta cosmovisión y en ciertos imaginarios) que, en última instancia, han convertido a la especie humana en una exterioridad agresiva y cancerosa que sólo sabe relacionarse con el hábitat natural de una forma depredadora. Sin olvidar, y hemos de remarcarlo una vez más, que la depredación económica está precedida (y, por lo tanto, posibilitada) por una depredación epistémica.

En tal contexto de preocupaciones civilizatorias surge como alternativa la "ecología de los saberes", un concepto propuesto por Boaventura de Sousa Santos, y que puede entenderse como una metodología investigativa alternativa que privilegia la interactividad sobre la unilateralidad, proponiendo una suerte de convivencia dialogante e intercambiadora (no jerárquica) entre quienes pretenden poseer el único conocimiento científico válido y aquellos sectores de la población o aquellas culturas que poseen otro tipo de conocimientos o saberes (populares, ancestrales, no-occidentales). En ese sentido, apunta que las ciencias sociales hegemónicas han sido excesivamente "monoculturales", es decir, han hundido sus raíces sólo en el saber propio de la moderna cultura occidental. La ecología de saberes, sin embargo, señala que existe una enorme variedad de conocimientos a lo largo y ancho del mundo y asume, además, un presupuesto que el canon epistemológico eurocéntrico nunca estuvo dispuesto a admitir: los distintos saberes pueden coexistir, sin necesidad de que unos aplasten, ridiculicen o silencien a los otros ${ }^{73}$.

$\mathrm{Si}$, históricamente, hemos asistido a construcciones rígidamente monoculturales (con respecto al saber, a la subjetividad, a la sexualidad o a la productividad, por ejemplo) lo que habríamos de desarrollar ahora son ecologías (de saberes, de temporalidades, de productividades). Dentro de ellas, la ecología de las productividades es muy útil para luchar contra el extractivismo predatorio, que "consiste en la recuperación y valorización de los sistemas alternativos de producción, de las organizaciones económicas populares, de las cooperativas obreras, de las empresas autogestionadas, de la economía solidaria, etc., que la ortodoxia productivista capitalista ocultó o desacreditó". Sousa Santos también ha criticado de forma muy sugestiva esa visión extremadamente reduccionista de la naturaleza, que la contempla (y, por ende, la trata) desde una óptica exclusivamente productivista ${ }^{74}$. En este sentido, todo lo que se considera de utilidad (para Occidente) es extraído (mediante apropiación violenta o fraudulenta) a los pueblos o comunidades indígenas (destruyendo su entorno cultural y esquilmando su hábitat natural) para beneficio de empresas o entes públicos completamente ajenos a ellos. Podríamos hablar, incluso, de una suerte de "extractivismo estético", cuando ciertas empresas occidentales acuden a estas comunidades para observar, copiar y replicar la forma de hacer tejidos o de combinar colores.

En ese mismo horizonte, podemos rescatar propuestas que precisamente critican, desde Latinoamérica y Asia, los procesos extractivistas que están destruyendo el planeta a ritmo vertiginoso. Por una parte, la República del Ecuador ha incluido en su constitución de 2008 los denominados derechos de la naturaleza, los cuales son asimismo objetivo de los planes de desarrollo (Plan Nacional del Buen Vivir) de este país. Por ejemplo, los artículos

\footnotetext{
${ }^{73}$ Boaventura de Sousa Santos, "Más allá del pensamiento abismal: de las líneas globales a una ecología de saberes", en Heriberto Cairo Carou (Ed.), Ramón Grosfoguel (Ed.), Descolonizar la modernidad, descolonizar Europa. Un diálogo Europa-América Latina, 101-146, 2010.

74Boaventura de Sousa Santos, Descolonizar el saber, reinventar el poder, Montevideo, Ediciones Trilce, 2010.
} 
14, 71 y 414 hablan del derecho a vivir en ambientes sanos, sustentables, ecológicamente equilibrados; y en donde se debe respetar a la Pacha Mama y a la regeneración de la naturaleza; e incluso se insta a que el Estado genere políticas públicas que mitiguen el cambio climático y protejan a poblaciones en riesgo. La del Ecuador es la única Constitución del mundo que reconoce que la naturaleza tiene derechos intrínsecos, más allá de la utilidad que los seres humanos puedan obtener de ella. Lo cual, evidentemente, ha conllevado un cierto replanteamiento crítico de los modelos de desarrollo socioeconómico hasta entonces hegemónicos ${ }^{75}$. En otros proyectos políticos latinoamericanos, más explícitamente socialistas, también se consideró (al menos en un nivel discursivo) el asunto de los límites de la naturaleza sobrepasados una y otra vez por la implacable lógica del modo de acumulación capitalista ${ }^{76}$.

Y resulta interesante, de igual modo, considerar las propuestas de la pensadora india Vandana Shiva77, que desde su "ecofeminismo" señala que el sometimiento de las mujeres se estructura (y se expande) en base a la misma lógica que el sometimiento de la naturaleza; los feminicidios y los ecologicidios estarían secretamente conectados, pues ambos responderían a una misma objetivación cosificadora y, por lo tanto, el patriarcado es per se devastador y depredador tanto de los cuerpos como del medio ambiente. El patriarcado subalterniza a las mujeres colocándolas como parte de la naturaleza, algo que explica bien Sherry Ortner 78 en un texto ya clásico que precisamente lleva por título: “¿Es la mujer con respecto al hombre lo que la naturaleza respecto a la cultura?". La maniobra discursiva consiste en establecer el binomio "varón-cultura" y el binomio "mujernaturaleza", postulado que el primer par siempre debe dominar al segundo par. Todo lo cual responde, a su vez, a la configuración histórica de un sistema económico productivista y depredador. "A partir de la revolución científica europea, la economía se convirtió de prudente administración de los recursos para el sustento y satisfacción de las necesidades básicas en un proceso de producción de bienes para hacer el máximo de ganancias, eliminando las implicaciones éticas y cognoscitivas que pudieran impedir esa explotación"79. Esa lógica económica siempre estuvo retroalimentada por una tecnociencia que, a su vez, se fundamentaba en una manera muy precisa de conocer la naturaleza. $Y$, en ese entramado de saberes-poderes, las mujeres fueron situadas en ese ámbito de lo "natural" que siempre debe ser domeñado. "En su afán por sobrevivir a los ataques de la ciencia y el desarrollo, las mujeres han comenzado una lucha que desafía las categorías principales del patriarcado occidental: los conceptos de naturaleza y mujer, y los de ciencia y desarrollo. Están desafiando el supuesto universalismo de la ideología patriarcal no con otra tendencia universalista sino con la diversidad; y están desafiando el concepto dominante de poder como violencia con el concepto alternativo de la no violencia como

\footnotetext{
75Rickard Lalander, "Rights of nature and the indigenous peoples in Bolivia and Ecuador: A Straitjacket for Progressive Development Politics?", Iberoamerican Journal of Development Studies, 3 (2), 148-173, 2014.

76Paula Vidal, Manuel Ansaldo y Juan Carlos, "Hugo Chávez y los principios del Socialismo del Siglo XXI: una indagación discursiva (2005-2013)", Izquierdas, 42, octubre, 224-250, 2018.

77Vandana Shiva, “Abrazar la vida. Mujer, ecología y desarrollo”, Cuadernos Inacabados, No 18, Madrid, Horas y Horas, 1995.

78Sherry Ortner, “¿Es la mujer con respecto al hombre lo que la naturaleza respecto a la cultura?”, en Harris, Olivia y Kate Young (Comp.), Antropología y feminismo, Anagrama, Barcelona, 109-131, 1979.

79Shiva, op. cit., p. 1.
} 
poder" 80 . Un ecofeminismo que, y esto lo hace aún más interesante desde una óptica decolonial, se elabora en una sociedad no occidental, aportando herramientas intelectuales muy valiosas a la hora de analizar múltiples estructuras de dominio que, desde hace siglos, someten a las mujeres y depredan la naturaleza.

\section{Conclusiones}

¿Qué tiene que ver Francis Bacon con la tala indiscriminada de árboles en la Amazonía? ¿Y Descartes con la extracción altamente contaminante de minerales e hidrocarburos? ¿Acaso la filosofía natural newtoniana puede tener algo que ver con esas compañías transnacionales dedicadas a la agricultura transgénica y a los agresivos monocultivos intensivos? A primera vista, podría parecer descabellado establecer semejante conexión. Pero, trazando una genealogía crítica de la episteme europea, podría llegar a sostenerse que las relaciones con la naturaleza hoy hegemónicas (nuestra forma de pensarla, de concebirla y de intervenirla) tienen mucho que ver con la configuración histórica de aquella objetivación científica de la naturaleza puesta en marcha por la modernidad europea; objetivación que, a su vez, formó parte constitutiva de las relaciones de dominio y los patrones de poner impuestos por el sistema-mundo moderno y eurocentrado. Porque la colonialidad del saber incluye, dentro de su repertorio, una específica colonialidad de la naturaleza; esto es, una colonialidad en la forma de entenderla, explicarla y tratarla.

Los análisis y las propuestas que, sucintamente, hemos expuesto a lo largo de este trabajo nos permiten comprender que existen formas de pensar y actuar distintas a las lógicas predatorias de la modernidad capitalista. Si la racionalidad cartesiana, implementada a toda máquina en las sociedades industriales europeas, propuso formas de entender el mundo que colocaban en un plano de superioridad absoluta a la tecnología sobre la naturaleza, es quizás momento de revertir o al menos mitigar tal situación, que pone en serio peligro la sostenibilidad ambiental del planeta. Para ello, será imprescindible cuestionar muy profundamente la legitimidad de todos esos discursos que pretenden defender la inexorabilidad del extractivismo económico más desaforado, apoyándose en fetiches ideológicos como el "desarrollo" y el "progreso". Sin olvidar, por otro lado, que tales procedimientos vienen acompañados (es más, posibilitados) por ciertas formas de "extractivismo epistémico" y, en último término, por traumáticos "epistemicidios".

Como ha señalado Arturo Escobar, la naturaleza no existe ahí afuera, como una entidad ya constituida, toda vez que siempre es construida desde ciertas coordenadas epistémicas81; por lo tanto, existen otros modos diferentes de concebir e imaginar la naturaleza, más allá de la forma hegemónica impuesta globalmente por el canon epistémico eurocéntrico. Porque, aunque el triturador extractivismo lleva operativo más de cinco siglos, la sofisticación tecnológica ultramoderna lo ha venido intensificado notable y dramáticamente ${ }^{82}$. Y es que externalizar la naturaleza con respecto a la cultura,

80Shiva, op. cit., p. 1.

${ }^{81}$ Arturo Escobar, El lugar de la naturaleza y la naturaleza del lugar: ¿globalización o postdesarrollo?, Buenos Aires, CLACSO, 2000.

${ }^{82}$ Héctor Alimonda (Coord.), La naturaleza colonizada. Ecología política y minería en América Latina, Buenos Aires, CLACSO, 2011. 
entendida ésta como una civilización insaciable que debe impactar, mediante tecnologías cada vez más agresivas y violentas, sobre ella, constituye la condición para la apropiación/explotación que está en la base del paradigma occidental del crecimiento sin límite. De ese modo se ha venido produciendo el "desarrollo" más desalmado, en lo que a la problemática ambiental se refiere. Por ello, las alternativas al imperante (e imperial) modelo cartesiano-matemático proliferan en múltiples lugares, como hemos podido ver.

Quizá sea el momento, al calor de las teorías aquí expuestas y de otras muchas que están por aparecer, de analizar la naturaleza como algo múltiple; esto es, quizás sea el momento de deseuropeizarla, deconstruirla, interculturalizarla y despatriarcalizarla para, de tal modo, empezar a preservarla. La Naturaleza, inscrita en el frontispicio de la modernidad occidental con letras mayúsculas, es un a priori sobre el que se ha venido sustentando un modelo civilizatorio extremadamente predatorio. Frente a esto, en múltiples partes del planeta, han emergido diversas teorizaciones, cosmovisiones y pensamientos holísticos (no jerárquicos) que comprenden la existencia de naturalezas (en plural, y con minúsculas) múltiples e inclusivas. Decía Bruno Latour que "nunca fuimos modernos" 83 . Pero, en realidad, lo que terminó sucediendo es que "fuimos demasiado modernos" en algunas cuestiones, por ejemplo, en lo que se refiere al imperativo de "dominar la naturaleza". Bien es verdad, en cualquier caso, que si la modernidad eurocentrada desembocó en un proyecto civilizatorio ecologicida -radicalmente incompatible, en suma, con la sustentabilidad ambiental del planeta- fue, en verdad, porque dicha modernidad devino indistinguible del modo de producción capitalista y de la sociedad de mercado. Lo cual nos hace pensar, aunque esta cuestión es ya objeto de otro estudio, que otras posibles modernidades europeas quedaron abortadas y sumergidas.

\section{Referencias bibliográficas}

- Acosta, Alberto. 2014. "Post-crecimiento y post-extractivismo: dos caras de la misma transformación cultural". En Gustavo Endara (Edit.), Post-crecimiento y Buen Vivir. Propuestas globales para la construcción de sociedades equitativas y sustentables, FES EcuadorILDIS, Quito, 2014: 93-122.

- Adorno, Theodor y Max Horkheimer. 2004. Dialéctica de la Ilustración. Madrid, Trotta.

- Agrawal, Arun. 2005. Environmentality. Technologies of Government and the Making of Subjects. Durham and London: Duke University Press.

- Alimonda, Héctor. (Coord.). 2011. La naturaleza colonizada. Ecología política y minería en América Latina. Buenos Aires, CLACSO.

- Arenas, Luis. 1996. "De lo uno a lo otro: conocimiento, razón y subjetividad en Descartes". Anales del Seminario de Historia de la Filosofía, No 13: 97-124.

- Arenas, Luis. 2002. Identidad y subjetividad. Materiales para una historia de la filosofía moderna. Madrid, Biblioteca Nueva.

- Bacon, Francis. 2011. La gran restauración (Novum Organum). Madrid, Tecnos.

\footnotetext{
83Bruno Latour, Nunca fuimos modernos. Ensayo de antropología simétrica, Buenos Aires, Siglo Veintiuno, 2007.
} 
- Bauman, Zygmunt. 2005. Vidas desperdiciadas. La modernidad y sus parias. Buenos Aires: Paidós.

- Benjamin, Walter. 2009. La dialéctica en suspenso. Fragmentos sobre la historia. Santiago de Chile, LOM.

- Bergson, Henri. 2006. Ensayo sobre los datos inmediatos de la conciencia. Salamanca, Sígueme.

- Butler, Judith. 2006. Vida precaria: el poder del duelo y la violencia. Barcelona: Paidós.

- Burtt, Edwin Arthur. 1960. Los fundamentos metafísicos de la ciencia moderna. Buenos Aires, Editorial Sudamericana.

- Cassirer, Ernst. 1975. Filosofía de la Ilustración. México, Fondo de Cultura Económica.

- Castro-Gómez, Santiago. 2011. La colonialidad del saber: eurocentrismo y ciencias sociales. Buenos Aires, Fundación Centro de Integración, Comunicación, Cultura y Sociedad (CICCUS), Consejo Latinoamericano de Ciencias Sociales (CLASCO).

- Castro-Gómez, Santiago. 2015. Revoluciones sin sujeto. Slavoj Žižek y la crítica del historicismo posmoderno. México: Akal.

- De Sousa Santos, Boaventura. 2010a. "Más allá del pensamiento abismal: de las líneas globales a una ecología de saberes". En Heriberto Cairo Carou (Ed.), Ramón Grosfoguel (Ed.), Descolonizar la modernidad, descolonizar Europa. Un diálogo Europa-América Latina: 101-146.

- De Sousa Santos, Boaventura. 2010b. Descolonizar el saber, reinventar el poder. Montevideo, Ediciones Trilce.

- Descartes, René. 1990. El tratado del hombre. Madrid, Alianza.

- Descartes, René. 2002. Discurso del método y Meditaciones metafísicas. Madrid, Tecnos.

- Descartes, René. 2003. Reglas para la dirección del espíritu. Madrid. Alianza.

- Descola, Philippe. 2012. Más allá de naturaleza y cultura. Buenos Aires: Amorrortu.

- Dirlik, Arif. 1997. The poscolonial aura. Third world criticism in the age of global capitalism. Boulder: Westview Press.

- Echeverría, Bolívar. 1994. Modernidad, mestizaje cultural, ethos barroco. México: UNAM.

- Escobar, Arturo. 2000. El lugar de la naturaleza y la naturaleza del lugar: iglobalización o postdesarrollo? Buenos Aires, CLACSO.

- Foucault, Michael. 1999. "La gubernamentalidad". En M. Foucault, Obras esenciales. Volumen III: Estética, ética y hermenéutica. Barcelona: Paidós: 175-198.

- Foucault, Michael. 2007. Nacimiento de la Biopolítica. Curso en el Collège de France (19781979). México y Buenos Aires: Fondo de Cultura Económica.

- Galeano, Eduardo. 2004. Las venas abiertas de América Latina. Madrid, Siglo XXI.

- Galileo. 1991. Antología. Barcelona, Península.

- Galison, Peter. 2005. Relojes de Einstein y mapas de Poincaré. Los imperios del tiempo. Barcelona, Crítica.

- Grosfoguel, Ramón. 2013. "Racismo/sexismo epistémico, universidades occidentalizadas y los cuatro genocidios/epistemicidios del largo siglo XVI". Tabula Rasa, 19: 31-58.

- Grosfoguel, Ramón. 2016. “Del «extractivismo económico» al «extractivismo epistémico» y «extractivismo ontológico»: una forma destructiva de conocer, ser y estar en el mundo". Tabula Rasa, 24: 123-143. 
- Gudynas, Eduardo. 2013. “Extracciones, extractivismos y extrahecciones: un marco conceptual sobre la apropiación de los recursos naturales". Observatorio del Desarrollo, 18: 1-18.

- Guha, Ranajit. 2002. Las voces de la historia y otros estudios subalternos. Barcelona: Crítica.

- Hard, Michael, \& Negri, Antonio. 2004. Multitud. Guerra y democracia en la era del Imperio. Buenos Aires: Debate.

- Heidegger, Martin. 2003. Filosofía, ciencia y técnica. Santiago de Chile, Editorial Universitaria.

- Horkheimer, Max. 2002. Crítica de la razón instrumental. Madrid, Trotta.

- Koyré, Alexandre. 1980. Estudios galileanos. Madrid, Siglo Veintiuno.

- Lalander, Rickard. 2014. "Rights of nature and the indigenous peoples in Bolivia and Ecuador: A Straitjacket for Progressive Development Politics?". Iberoamerican Journal of Development Studies, 3 (2): 148-173.

- La Mettrie, J. O. 1987. El hombre máquina. Madrid, Alhambra.

- Lander, Edgardo. 2004. “Ciencias sociales. Saberes coloniales y eurocéntricos”. En La colonialidad del saber: eurocentrismo y ciencias sociales. Perspectivas latinoamericanas, Caracas, Faces- UCV / Unesco-Iesalc.

- Laplace, P. S. 2006. Exposición del sistema del mundo. Barcelona, Crítica.

- Latour, Bruno. 2007. Nunca fuimos modernos. Ensayo de antropología simétrica. Buenos Aires, Siglo Veintiuno.

- Leff, Enrique. 2004. Racionalidad ambiental. La reapropiación social de la naturaleza. México, Siglo Veintiuno.

- Lyotard, J. F. 1990. La condición posmoderna. Informe sobre el saber. México: Ediciones Rei.

- Luxemburgo, Rosa. 1967. La acumulación del capital. México, Grijalbo.

- Marcuse, Herbert. 1987. El hombre unidimensional. Barcelona, Ariel.

- Mariátegui, José Carlos. 2007. Siete ensayos de interpretación de la realidad peruana. Caracas: Ayacucho.

- Montenegro-Perini, Iván. 2017. “Ecoturismo, gubernamentalidad neoliberal y despojos en la Amazonia colombiana". Universitas Humanística, (84), 35-73.

- Mignolo, Walter. 2003. Historias locales/diseños globales. Colonialidad, conocimientos subalternos y pensamiento fronterizo. Madrid, Ediciones Akal.

- Moore, J. W. 2013. “El auge de la ecología-mundo capitalista. Las fronteras mercantiles en el auge y decadencia de la apropiación máxima", Laberinto, $\mathrm{N}^{\mathrm{0}}$ 38: 9-26.

- Ortner, Sherry. 1979. “¿Es la mujer con respecto al hombre lo que la naturaleza respecto a la cultura?". En Harris, Olivia y Kate Young (Comp.), Antropología y feminismo. Editorial Anagrama, Barcelona, 1979: 109-131.

- Polanyi, Karl. 2014. "El eclipse del pánico y las perspectivas del socialismo", en César Rendueles (Eds.), Los limites del mercado. Reflexiones sobre economía, antropología y democracia, Madrid, Capitán Swing: 123-126.

- Polo Blanco, Jorge. 2017. "Mercantilización de la naturaleza, biocentrismo radical, extractivismo y desarrollo humano. Las inevitables paradojas de una política pública que reconoce derechos intrínsecos a la naturaleza", Revista de Filosofía, Universidad del Zulia, Venezuela, No 87: 48-70. 
- Quijano, Aníbal. 2000a. “Colonialidad del Poder, Eurocentrismo y América Latina”. En Lander, Edgardo (Comp.), Colonialidad del Saber, Eurocentrismo y Ciencias Sociales. Perspectivas latinoamericanas, Buenos Aires, CLACSO.

- Quijano, Aníbal. 2000b. "Colonialidad del poder y clasificación social". Journal of WorldSystems Research, Volume 6, Issue 2, Special Issue Festschrift for Wallerstein: 342-386.

- Rescher, Nicholas. 1993. La racionalidad. Madrid, Tecnos.

- Sassen, Saskia. 2015. Expulsiones: brutalidad y complejidad en la economía global. Buenos Aires: Katz.

- Segato, Rita Laura. 2013. “Ejes argumentales de las perspectivas de la colonialidad del poder". Revista Casa de las América, N²72, julio-septiembre 2013: 17-39.

- Shiva, Vandana. 1995. "Abrazar la vida. Mujer, ecología y desarrollo". Cuadernos Inacabados, $\mathrm{N}^{\mathrm{o}} 18$. Madrid, Horas y Horas.

- Suarez Navas, Liliana. 2008. "Colonialismo, gobernabilidad y feminismos poscoloniales". En Descolonizando el feminismo: teorías y prácticas desde los márgenes. Madrid: Cátedra.

- Thompson, Edward. P. 1974. "La economía moral de la multitud en la Inglaterra del siglo XVIII", Revista de Occidente, No 133, 1974: 54-125.

- Ulloa, Astrid. 2005. The Ecological Native. Indigenous Peoples' Movements and Ecogovernmentality in Colombia. New York: Routledge.

- Vidal, Paula; Ansaldo, Manuel y Juan Carlos Cea. 2018. "Hugo Chávez y los principios del Socialismo del Siglo XXI: una indagación discursiva (2005-2013)", Izquierdas, 42, octubre: 224-250.

- Virno, Paolo. 2003. Gramática de la multitud. Para un análisis de las formas de vida contemporánea. Madrid: Traficantes de Sueños.

- Viveiros de Castro, Eduardo. 2010. Metafísicas caníbales. Líneas de antropología postestructural. Buenos Aires, Madrid, Katz.

- Walsh, Catherine. 2005. "Interculturalidad, conocimientos y decolonialidad". Signo y Pensamiento, Volumen XXIV, No 46, enero-junio: 39-50.

- Walsh, Catherine. 2007. “Son posibles unas ciencias sociales/culturales "otras”? Reflexiones en torno a las epistemologías decoloniales". Revista Nómadas, N²6, abril, 2007: 102-112.

- Weber, Max. 1983. Historia económica general. México, Fondo de Cultura Económica.

- Wolf, Eric R. 1987. Europa y los pueblos sin historia. México, Fondo de Cultura Económica. 